\title{
Zdenek Holub \\ Laparoscopic management of early endometrial cancer: current status
}

Received: 9 March 2006 / Accepted: 8 June 2006 / Published online: 5 August 2006

(C) Springer-Verlag Berlin / Heidelberg 2006

\begin{abstract}
Endometrial cancer is the most common form of gynaecological cancer. Laparotomy has traditionally been the surgical treatment of choice, but the laparoscopic approach is gaining wider acceptance by gynaecologic surgeons, and an abundance of clinical information is currently available on all aspects of this approach. Whether in combination with laparoscopic-assisted vaginal or total laparoscopic hysterectomy, laparoscopic staging, including salpingo-oophorectomy and regional lymph-node dissection, is a major component of the treatment of patients with early endometrial cancer. This review examines the various options to treating endometrial cancer and proposes that laparoscopically assisted surgical staging of endometrial cancer is both a feasible and safe option. Comparative analyses of survival and recurrence rates for patients treated by laparoscopy and laparotomy have shown similar survival results. It remains to be proven if these laparoscopic techniques are associated with greater benefits.
\end{abstract}

Keywords Endometrial cancer - Laparoscopy · Management

\section{Introduction}

Endometrial cancer (EC) is the most common form of gynaecological cancer with an incidence of 48.7 cases per 100,000 women in the USA and $32,00 / 100,000$ in the Czech Republic [1,2]. Fortunately, most women present with early-stage disease and have an excellent prognosis. For the medically operable candidates with early-stage disease, surgery is the treatment of choice, with laparotomy being the traditional approach. However, the laparoscopic approach is gaining wider acceptance by gynaecologic

\footnotetext{
Z. Holub $(\bowtie)$

Department of Obstetrics and Gynecology,

Endoscopic Training Centre, Baby Friendly Hospital,

27258 Kladno, Czech Republic

e-mail: holubz@seznam.cz

Tel.: +420-312-606383

Fax: $+420-312-606417$
}

surgeons. Laparoscopy offers a number of major advantages over laparotomy for patients undergoing surgical treatment for benign gynaecological disorders. Similar advantages have been found in women undergoing laparoscopic radical surgery for uterine malignancies. Consequently, there is a growing body of evidence in the literature favouring laparoscopic techniques over the standard laparotomy approach for patients with endometrial cancer [3]. Since the first report by Childers et al. [4] on laparoscopically assisted surgical staging (LASS) several reports have followed.

The following review will update our present knowledge as to the benefits and results of laparoscopy in the treatment of women with surgically manageable early endometrial cancer.

\section{Laparoscopic surgical techniques}

Whether in combination with laparoscopic assisted vaginal hysterectomy (LAVH) or total laparoscopic hysterectomy (TLH), laparoscopic staging, including lymphadenectomy, is a major component in the treatment of patients with early-stage endometrial cancer. It remains to be proven which of these techniques is associated with the greatest benefits [5]. The standard approach to the surgical management of early-stage endometrial carcinoma has been to perform the primary surgery via an open technique. Peritoneal washing is obtained for cytology, a thorough exploratory laparotomy is performed and an extrafascial hysterectomy and bilateral salpingo-oophorectomy (BSO) are carried out. Pelvic and para-aortic lymph node dissections complete the surgical staging.

\section{Laparoscopic hysterectomy and bilateral salpingo-oophorectomy}

The traditional surgical approach to EC has been an abdominal hysterectomy ( $\mathrm{AH}$ ) and adnexectomy, which is the current gold standard of care as documented by 
Patridge et al. [6]. This surgical procedure has been performed on $80 \%$ of American women with endometrial cancer. Vaginal hysterectomy has long been viewed as an acceptable alternative for some women with endometrial cancer for whom total abdominal hysterectomy might be difficult or risky [7]. However, it may be difficult or impossible to inspect the peritoneal cavity, obtain peritoneal cytology and perform salpingo-oophorectomy and lymph node dissection by means of the vaginal approach. The shortcomings of the pure vaginal approach have recently been documented in a study on laparoscopy [8]. Laparoscopic-assisted vaginal hysterectomy combined with laparoscopic lymphadenectomy in the management of endometrial cancer has been reported in several series totalling over 600 patients [9]. Most of the gynaecologic surgeons performing laparovaginal hysterectomy, particularly LAVH, find this approach to be safer and shorter than a purely laparoscopic approach $[10,11]$.

Although various techniques of TLH have been reported [12-14], no prospective or randomised studies have reported on its efficiacy in the management of endometrial cancer. In a retrospective study Manolitsas and McCartney [14] compared TLH with open hysterectomy in the management of endometrial carcinoma. The authors developed a safe and efficient technique for performing TLH using a specially designed silicone, transvaginal tube. The low incidence of port-site metastases was reported by Obermaier et al. [12] in a group of 226 women with earlystage endometrial cancer treated by TLH. These authors concluded that TLH management does not seem to worsen the prognosis of patients with EC. A comparison of TLH and abdominal hysterectomy for obese women with endometrial cancer revealed that wound infection occurred in $48.8 \%$ patients in the abdominal group and in $2.1 \%$ in the TLH group. All other morbidity, as well as patterns of recurrence and survival rates, were similar in both groups. These data justify a prospective randomised trial comparing TLH with abdominal hysterectomy for the treatment of endometrial cancer.

However, other surgical approaches are also able to achieve the standard recommendation for the management of early-stage endometrial cancer. Fagotti et al. [15] suggest that mini-laparotomy is a feasible alternative to the standard treatment in endometrial cancer patients as it offers the patient a cost-effective procedure that avoids many of the potential complications of standard therapy.

\section{Laparoscopic lymph node dissection}

Given that lymphadenectomy is accepted as standard management of uterine cancer, there is no reason for not replacing the classical open procedure with the laparoscopic one. Two laparoscopic approaches to lymphadenectomy have been developed: extraperitoneal and transperitoneal. The extraperitoneal approach was the first to be developed, and it may offer some advantages over the transperitoneal approach. It has been experimentally demonstrated that the extraperitoneal approach generates significantly fewer adhesions than the transperitoneal technique, which allows adjuvant radiotherapy to be started sooner with reduced morbidity $[16,17]$. On the other hand, the transperitoneal approach is the most extended technique among laparoscopic surgeons and, consequently, this approach allows lymphadenectomy and hysterectomy to be combined with salpingo-oophorectomy.

The area in which the superiority of the laparoscopic tool has been clearly demonstrated is with the prevention of postoperative adhesions. This is a significant advantage in the management of endometrial cancer because patients who are considered to be at risk for recurrence after lymphadenectomy are subjected to radiotherapy. For radiotherapy, the complication of greatest concern is radiation enteritis, a complication that is linked to peritoneal adhesions' limiting the mobility of the intestinal loops and exposing them to excessive irradiation [8].

A retrospective comparative study by Leblanc et al. [19] found six severe complications in 26 patients irradiated following open pelvic dissection, versus one complication for 26 patients irradiated after laparoscopic dissection. Although the laparoscopic approach to lymph node dissection seems to be better than the open approach, laparoscopic dissection could be improved if limited to the sentinel lymph node biopsy. This issue is discussed in the following section.

\section{Laparoscopic pelvic and para-aortic lymphadenectomy}

Laparoscopic pelvic lymphadenectomy was first reported in 1991 by Querleu et al. [20] in a series of 39 patients with cervical cancer in. One year later Nezhat et al. [21] described para-aortic lymphadenectomy for the first time.

The number of reports on the use of laparoscopy in lymph node dissection in endometrial cancer remains surprisingly low $[4,8,10-13,16-20,22-24]$. Childers et al. [4] reported on a series of 59 patients considered to be candidates for LASS for the management of clinical stage I adenocarcinoma of the endometrium. These authors carried out pelvic and para-aortic lymphadenectomy on 23 patients, but were unable to perform the common iliac and para-aortic lymphadenectomy by laparoscopy in two other patients because of obesity. Several authors have concluded that removal of both the pelvic and para-aortic lymph nodes can be accomplished laparoscopically even in obese patients $[10,13,25,26]$. However, at present, there is no consensus on indication and extent with regard to lymphadenectomy. Even in the presence of other pelvic pathology, obesity does not seem to limit pelvic lymphadenectomy, thus allowing these women with endometrial cancer to be candidates for the laparoscopic procedure [25]. In addition, primary removal of the aortic nodes is not warranted in most women with endometrial carcinoma and should be restricted to the pelvic lymph nodes [27].

Holub et al. [28] reported the findings of a Czech multicentric study in which transperitoneal lymph node dissection was used. Among the 69 patients in the laparoscopic group with higher stage grading and deep myometrial invasion, pelvic node dissection only was 
carried out in 44 patients, and both pelvic and para-aortic lymphadenectomy were also done in 25 of the patients. Malignant changes in the lymph nodes were confirmed in ten of these women $(14.5 \%)$ and in one woman in the group of patients with low grading and a myometrial myoinvasion of less than $50 \%$. The total number of women with pathologic lymph nodes and positive peritoneal cytology was $14(15.2 \%)$. In such cases as these clinical evaluation alone may lead to understaging of the disease. In a retrospective chart review of 320 patients with early-stage endometrial cancer treated by laparoscopic hysterectomy and lymphadenectomy or total abdominal hysterectomy and lymphadenectomy described by Gemignani et al. [29], no significant difference existed between either method in mean lymph node yield. However, pelvic node metastasis was found to be a better criterion for aortic lymphadenectomy than myometrial invasion. According to the findings of Benedetti-Panici et al. [30], the superficial obturator nodes in the pelvic area were frequently involved. Evaluation of these nodes alone identified $71 \%$ of patients with positive nodes. On the other hand, when the external iliac and superficial common iliac nodes were evaluated together with the superficial obturator group, all patients with metastases were identified.

In one randomised prospective clinical trial, 37 patients with EC were treated with a laparoscopic assisted approach and 33 patients with an abdominal approach [11]. In the first group of patients, pelvic lymphadenectomy was performed in 25 women and para-aortic lymphadenectomy in 20. In the second group, pelvic and para-aortic lymphadenectomy were performed in 24 and 20 patients, respectively. No major intra-operative complications occurred in either group, and conversion was not necessary. Postoperative complications were not severe and were distributed similarly in both groups.

According to the recommendation of the FIGO Committee on Gynecologic Oncology [31], indication for aortic lymph node dissection would include suspicious aortic or common iliac nodes, grossly positive adnexa, grade 3 and any grade of tumour showing the outer half of myometrial invasion. Patients with clear cell papillary serous or carcinosarcoma histologic subtypes are also candidates for aortic sampling.

Although mandated through the staging system, lymphadenectomy of the pelvis and para-aortic areas remains controversial, with most individuals using selective node sampling and reserving regional total lymphadenectomy for cases with certain high-risk features.

\section{Laparoscopic uterine sentinel lymph node (SLN) biopsy}

The presence of lymph-node metastases has a major impact on the prognosis of women with uterine cancer. One of the cornerstones of gynaecologic cancer surgery is the assessment and removal of the regional lymph nodes. However, the most appropriate and reliable technique for assessing regional pelvic and para- aortic node remains uncertain [32]. The sentinel node is the first lymph node to receive cancer cell metastasis from the primary tumour. Sentinel lymph node dissection and intra-operative lymphatic mapping were, therefore, designed as a less invasive alternative to the routine elective lymph-node dissection in patients with early-early- stage cutaneous melanoma [33]. To date very few reports of cases of sentinel lymph node dissection in endometrial cancer have been published: approximately seven published studies (Table 1) are currently available that provide investigators with information which addresses the various questions concerning the detection of the SLN and its negative predictive value. The answers to these questions will determine the role of laparoscopic SLN biopsy in the management of early endometrial cancer.

\section{Targeting the nodes}

The sentinel node is targeted by injecting the marker close to the tumour. Injections in the fundus itself (using laparotomy, laparoscopy or hysteroscopy) have a higher detection rate but a lower predictive value [32, 34, 35]. In patients with endometrial cancer the injections can be made in the cervix as well. The technique as well as the medium used are important variables. Two types of media are used as a marker: blue dyes and radioisotopic colloids. The blue dyes [Lymphazurin or Patent Blue Dye (PBD)] can be used in undiluted or diluted form. The main reason for failure of the SLN PBD technique is likely to be the insufficient quantity of injected blue dye. A dose of at least $2 \mathrm{ml} \mathrm{PBD}$ in $7 \mathrm{ml}$ isotonic solution) is required. The site of injection also plays an important role. The depth of the injection should be $2-5 \mathrm{~mm}$ (the level of the sub-epithelial network). The observation reported by Dargent et al. [39] in patients with cervical cancer has bee confirmed by others in cases of
Table 1 Literature concerning SLN biopsy in early endometrial cancer

${ }^{\text {a }}$ RGS, Radio-guided surgery; BPD, Blue Patent Dye

\begin{tabular}{llllll}
\hline Author (reference) & $\begin{array}{l}\text { Number of } \\
\text { patients }\end{array}$ & $\begin{array}{l}\text { Injection } \\
\text { technique }^{\text {a }}\end{array}$ & $\begin{array}{l}\text { Surgical } \\
\text { technique }\end{array}$ & $\begin{array}{l}\text { SLN } \\
\text { detection (\%) }\end{array}$ & $\begin{array}{l}\text { Average } \\
\text { number of SLN }\end{array}$ \\
\hline Burke et al. [32] & 18 & PBD & Laparotomy & 67.0 & 2.0 \\
Holub et al. [31] & 25 & PBD & Laparoscopy & 84.0 & 2.0 \\
Pelosi et al. [34] & 16 & PBD+RGD & Laparoscopy & 94.0 & 1.5 \\
Barranger et al. [35] & 17 & PBD+RGS & Laparoscopy & 94.1 & 2.6 \\
Lelievre et al. [36] & 12 & PBD+RGS & Laparoscopy & 91.6 & 3.0 \\
Niikura et al. [37] & 28 & RGS & Laparotomy & 2.0 & 3.1 \\
Raspagliesi et al. [38] & 18 & RGS & Hysteroscopy & 100.0 & 3.0 \\
\hline
\end{tabular}


endometrial cancer [40]: successful SND detection depends on both the sites of injection and the volume of BPD.

Albumin and synthetic colloidal particles are used as radiocolloids. No matter which colloid is used, however, the detection rate is higher and the number of detected nodes is greater with the radioisotopic technique than with the blue dyes, although the false negative rate may also be higher with the former. The combination of blue dye and isotopes is obviously the most productive tool [18].

\section{Locating and removing the nodes}

Following the injection of the radioisotopic colloid the targeted nodes can be located transcutaneously by means of scintigraphy. The most common isotope used for linking to the colloid particles is technetium 99. The surgical localisation of the SLN can be undertaken up to $12 \mathrm{~h}$ after the injection of the colloid, but with the injection of blue dye, which Marchiole and Dargent [18] recommend in addition to the colloid, localisation must be made within minutes prior the beginning of surgery. The first step of the combined procedure recommended by these authors is a transperitoneal assessment. The laparoscope is introduced as usual. If the injection of BPD has been done correctly, the blue channels are located through the dorsal leaf of the broad ligament. The most frequent location is between the vein and the obturator nerve. In $85 \%$ of cases the targeted node lies in the interiliac area.

Assessing the nodes

The technique adopted for assessing the nodes has a major influence on the negative predictive value of the sentinel node biopsy. Although many different methods exist, these can be grouped into four categories: (1) frozen section, (2) unilevel sectioning and standard staining, (3) multilevel sectioning and histo-immunochemical staining and (4) molecular biology [18].

Unilevel sectioning and staining is the most commonly used tool, but true lymph node metastasis - a fortiori, micrometastases (tumour deposits less than $2000 \mu \mathrm{m}$ in size) and especially submicrometastases (tumour deposits less than $200 \mu \mathrm{m}$ in size) - can escape the assessment [18]. Multilevel sectioning is the answer to the inadequacy of classical techniques. A good compromise is editing two or three adjacent vignettes at selected $200-\mu \mathrm{m}$ intervals, a distance that theoretically avoids missing even submicrometastases. Immunohistochemical staining increases the sensitivity of the assessment.
Table 2 Comparison of perioperative laparoscopy and laparotomy data for endometrial cancer $^{\mathrm{a}}$

${ }^{a}$ The basic data were extracted from paper published by Magrina [3] with this author's permission

\begin{tabular}{llllll}
\hline Author (year and reference) & $\begin{array}{l}\text { Number of } \\
\text { patients }\end{array}$ & $\begin{array}{l}\text { Operating } \\
\text { time (min) }\end{array}$ & $\begin{array}{l}\text { Blood } \\
\text { loss (ml) }\end{array}$ & $\begin{array}{l}\text { Number of } \\
\text { lymph nodes }\end{array}$ & $\begin{array}{l}\text { Hospital } \\
\text { days }\end{array}$ \\
\hline Laparoscopy & & & & & \\
Magrina et al. (1995; [22]) & 15 & 174 & 272 & 18.5 & 3.4 \\
Spirtos et al. (1996; [56]) & 13 & - & - & 28.0 & 2.4 \\
Holub et al. (1998; [58]) & 11 & 153 & 130 & - & 4.7 \\
Gemignani et al. (1999; [29]) & 69 & 214 & 211 & 7.0 & 2.9 \\
Scribner et al. (2001; [57]) & 19 & 237 & 350 & 34.0 & 3.7 \\
Eltabbakh et al. (2000; [26]) & 40 & 195 & 318 & 11.3 & 2.5 \\
Holub et al. (2002; [31]) & 177 & 163 & 211 & 16.8 & 3.9 \\
Langebrekke et al. (2002; [46]) & 27 & 143 & - & 6.8 & 4.3 \\
Eltabbakh et al. (2001; [8]) & 100 & - & 200 & 13.5 & 2.0 \\
Litta et al. (2003; [24]) & 29 & 186 & 125 & 14.2 & 2.5 \\
Occelli et al. (2003; [16]) & 69 & 164 & - & 15.8 & 4.0 \\
Zapico et al. (2003; [48]) & 38 & 165 & - & 15.1 & 5.0 \\
Laparotomy & & & & & \\
Magrina et al. (1995; [22]) & 15 & 142 & 502 & 23.5 & 6.6 \\
Spirtos et al. (1996; [56]) & 17 & - & - & 29.0 & 6.4 \\
Holub et al. (1998; [58]) & 26 & 127 & 150 & - & 7.7 \\
Gemignani et al. (1999; [29]) & 251 & 144 & 209 & 6.0 & 6.7 \\
Scribner et al. (2001; [57]) & 17 & 157 & 344 & 30.0 & 5.2 \\
Eltabbakh et al. (2000; [26]) & 86 & - & 250 & 10.5 & 5.0 \\
Holub et al. (2002; [31]) & 44 & 115 & 246 & 14.3 & 7.3 \\
Langebrekke et al. (2002; [46]) & 24 & 87 & - & 5.6 & 6.2 \\
Eltabbakh et al. (2001; [8]) & 40 & 138 & 303 & 5.3 & 6.5 \\
Litta et al. (2003; [24]) & 30 & 152 & 153 & 13.4 & 6.4 \\
Occeli et al. (2003; [16]) & 58 & 123 & - & 11.0 & 9.0 \\
Zapico et al. (2003; [48]) & 37 & 130 & - & 13.5 & 7.0 \\
\hline
\end{tabular}


Pros and cons: systematic versus sentinel lymph node dissection

The aim of the sentinel node dissection is to avoid systematic lymphadenectomy in the lymph node-negative patient. Therefore, the SLN biopsy must meet two requirements. The first is surgical: the SLN biopsy must be less deleterious than the systematic dissection. The second is oncologic: the negative predictive value of the SLN assessment must be $100 \%$. The SLN biopsy is obviously more rapid and simpler than the systematic dissection, and the detection rate is between 90 and $100 \%$. The negative predictive value of the SLN assessment in most of the series reported in the literature is close to $100 \%$. On the other hand, systematic lymph node dissection, which, if done by laparoscope, is no more dangerous than the simple SLN biopsy, which is part of surgery for earlystage endometrial cancer.

\section{Laparoscopy versus laparotomy}

Perioperative data

Initial data reported by Magrina et al. [22] in comparing laparoscopy with laparotomy for the surgical treatment of patients with endometrial cancer revealed a number of advantages for the laparoscopic group. Additional studies have duplicated these preliminary results. A comparison of the perioperative data between laparoscopy and laparotomy for endometrial cancer is shown in Table 2. There is a general agreement that, relative to patients undergoing a laparotomy, laparoscopy patients have slightly longer operating times, reduced mean blood loss and hospitalisation and a similar, or larger, number of retrieved lymph nodes [3]. Of interest, consistently similar findings were also observed for both treatment groups when only patients with body mass indices (BMIs) between 28 and 60 were included [26]. Operating times, to no surprise, are in correlation with the surgeon's experience with this procedure. Decreasing operating times and an increased number of retrieved lymph nodes have been reported to be correlated with the increasing experience of the surgeon. The learning curve is believed to level off after 25-30 laparoscopic staging procedures for endometrial cancer [41].

Conversion to laparotomy and postoperative complications

Laparoscopic conversion rates to laparotomy range from 0 to $12.4 \%$ when all causes for conversion - severe adhesions, heavy bleeding, difficult exposure, obesity and intolerance to increased intra-abdominal pressure - are taken into consideration $[3,18,26,29]$. Of the TLH procedures $4-10.6 \%$ were converted to open hysterectomy $[12,14]$. However, conversion rates due to intraoperative complications are lower $(0-5.3 \%)$ [22-24, 29, 42, 43]. When the rate of postoperative complications are compared
Table 3 Follow-up and disease-free survival (DFS) for laparoscopy-treated women with endometrial cancer ${ }^{\mathrm{a}}$

\begin{tabular}{llll}
\hline Author (reference) & $n$ & $\begin{array}{l}\text { Mean follow up } \\
\text { (months) }\end{array}$ & DFS (\%) \\
\hline Magrina et al. [43] & 45 & 76.0 & 94.7 \\
Lim et al. [44] & 40 & 29.5 & 92.6 \\
Malur et al. [18] & 37 & 16.5 & 97.3 \\
Holub et al. [42] & 177 & 33.6 & 93.7 \\
Eltabbakh et al. [45] & 100 & 27.0 & 93.0 \\
Langebrekke et al. [46] & 27 & 12.0 & 100.0 \\
Liauw et al. [47] & 30 & 15.5 & 100.0 \\
Kuoppala et al. [23] & 40 & 34.0 & 100.0 \\
Zapico et al. [48] & 38 & 53.2 & 81.6 \\
Tozzi et al. [49] & 63 & 44.0 & 87.4 \\
Total and range & 597 & $12-76$ & $81.6-100.0$
\end{tabular}

${ }^{\mathrm{a}}$ The basic data were extracted from paper published by Magrina [3] with this author's permission

between laparotomy and laparoscopy techniques, similar or lower rates are noted for laparoscopy patients. The incidence of reported complications range from 0 to $17.5 \%[23,24]$.

\section{Survival and recurrence}

Several studies have evaluated the feasibility of laparoscopic surgery in women with endometrial cancer, but survival data are reported in only ten of these [18, 24, 4249] (Table 3). The disease-free survival (DFS) rate for a total of 597 patients followed up for a mean of 12-76 months ranged from $81.6-100 \%$. These values are not significantly different statistically from from laparotomy survival and recurrence rates (Tables 4 and 5). In a prospective randomised study $(n=70)$ Malur et al. [18] found no significant differences in disease recurrence and long-term survival between the laparoscopy and laparotomy groups (97.3 vs. $93.3 \%$ and 83.9 vs. $90.9 \%$, respectively). In seven patients death was related to cardiac

Table 4 Comparison of DFS between laparoscopy- and laparotomy-treated women with endometrial cancer ${ }^{\mathrm{a}}$

\begin{tabular}{lllll}
\hline Author (reference) & \multicolumn{4}{l}{ DFS (\%) } \\
\cline { 2 - 5 } & $n$ & Laparoscopy & $n$ & Laparotomy \\
\hline Malur et al. [18] & 37 & 97.3 & 37 & 93.3 \\
Holub et al. [42] & 177 & 93.7 & 44 & 93.2 \\
Eltabbakh et al. [45] & 100 & 90.0 & 86 & 92.0 \\
Langebrekke at al. [46] & 27 & 100.0 & 24 & 95.9 \\
Kuopalla et al. [23] & 40 & 100.0 & 40 & 95.0 \\
Zapico et al. [48] & 38 & 81.6 & 37 & 81.1 \\
Tozzi et al. [49] & 63 & 87.4 & 59 & 91.6 \\
\hline
\end{tabular}

${ }^{\mathrm{a}}$ The basic data were extracted from paper published by Magrina [3] with this author's permission

or pulmonary disorders and in two patients it was tumour- 
Table 5 Comparison of recurrence after treatment for endometrial cancer by laparoscopy and laparotomy ${ }^{\mathrm{a}}$

${ }^{\mathrm{a}}$ The basic data were extracted from paper published by Magrina [3] with this author's permission

\begin{tabular}{lllll}
\hline Authors (reference) & \multicolumn{3}{l}{ Recurrence (\%) } & \\
\cline { 2 - 5 } & $n$ & Laparoscopy & $n$ & Laparotomy \\
\hline Eltabbakh et al. [45] & 100 & 7.0 & 86 & 10.5 \\
Holub et al. [42] & 177 & 6.2 & 44 & 6.8 \\
Langebrekke et al. [46] & 26 & 0 & 22 & 4.1 \\
Kuoppala et al. [23] & 40 & 2.5 & 40 & 2.5 \\
Zapico et al. [48] & 38 & 5.2 & 37 & 5.4 \\
\hline
\end{tabular}

associated. In the Czech prospective multicentric study [42] no significant differences in tumour recurrence or long-term survival were found between laparoscopy and open surgery ( $p=0.99$ and $p=0.86$, respectively).

\section{Port-site metastases or recurrence}

The finding of tumour growth at the site of a previous laparoscopic trocar placement, commonly known as a portsite metastases (PSM), is one of the most feared complications of a laparoscopic procedure in gynaecologic cancer treatment. Port-site recurrence (PSR) has been reported in association with endometrial cancers managed laparoscopically; however, the mechanism of development is not fully understood $[50,51]$. In most cases these recurrences occur in association with advanced stage disease [41]. No patient in the reviewed series reported here experienced a trocar site recurrence (Tables 3 and 5). Muntz et al. [52] reported successfully treating a case of PSM after laparoscopic surgery for uterine cancer. Wilkinson et al. [53] concluded that laparoscopic PSR can be reproduced using the transplantable VX-2 rabbit carcinoma model. In the VX-2 model, trocar recurrence was the result of direct contamination via surgical instrumentation of viable cancer cells. The effect of the pneumoperitoneum or intra-peritoneal cytological spillage (indirect contamination) did not have any effect on trocar recurrence. However, the reported outcomes of studies on the impact of the pneumoperitoneum on tumour growth are controversial. Watson et al. [54] suggests that the excision of port-site wounds following laparoscopy for cancer in an experimental model does not prevent the subsequent development of port-site tumours. Most reports refer to the recurrence within the first 2 years. Two PSR reported by Sanjuan et al. [55] were discovered 39 and 48 months after first diagnosis, which is not frequent. The delay of these recurrences highlights the necessity of a randomised trial with longer follow-up.

\section{Conclusion}

This review illustrates that laparoscopic management of endometrial cancer is safe as an open procedure and that the survival and recurrence rates by this procedure are comparable to those of laparotomy. The laparoscopic approach may also be considered for endometrial malignancy which typically occur in obese, elderly, high-risk women. Laparoscopy affords a surgeon the ability to avoid abdominal incision wound infection in these patients. The laparoscopic approach also allows the women to have all of the benefits of minimally invasive surgery, such as less pain, less scaring, and a shorter recovery time. However, the relative difficulty for surgeons to develop advanced laparoscopic surgical skills is a limitation to the widespread use of laparoscopy.

\section{References}

1. Sherman ME, Carreon JD, Lacey JV, Devesa SS (2005) Impact of hysterectomy on endometrial cancer rates in the United States. J Natl Cancer Inst 97:1700-1702

2. Holub Z, Kuzel D (2005) Minimally invasive surgery in gynecology, 1st edn. Grada, Prague

3. Magrina JF (2005) Outcomes of laparoscopic treatment of endometrial cancer. Curr Opin Obstet Gynecol 17:343-346

4. Childers JM, Brzechffa PR, Hatch KD, Surwit EA (1993) Laparoscopically assisted surgical staging (LASS) of endometrial cancer. Gynecol Oncol 51:33-37

5. Magrina JF (2000) Laparoscopic surgery for gynaecologic cancers. Clin Obstet Gynecol 43:619-640

6. Patridge EE, Shingleton HM, Menck HR (1996) The National Cancer Data Base Report on endometrial cancer. J Surgeons Oncol 61:111-123

7. Massi G, Savino I, Susuni T (1996) Vaginal hysterectomy versus abdominal hysterectomy for the treatment of stage 1 endometrial carcinoma. Am J Obstet Gynecol 174:1320-1326

8. Eltabbakh GH, Shamonki MI, Moody JM, Garafano LL (2001) Laparoscopy as the primary modality for the treatment of women with endometrial carcinoma. Cancer 91:378-387

9. Holub Z (2003) The role of laparoscopy in the surgical treatment of endometrial cancer. Clin Exp Obstet Gynecol 30:7-9

10. Holub Z, Bartos P, Jabor A, Eim J, Fischlova D, Kliment L (2000) Laparoscopic surgery in obese women with endometrial cancer. J Am Assoc Gynecol Laparosc 7:83-88

11. Malur S, Possover M, Michaels W, Schneider A (2001) Laparoscopic-assisted vaginal versus abdominal surgery in patients with endometrial cancer: a prospective randomized study. Gynecol Oncol 80:239-244

12. Obermeier A, Manolitsas TP, Leung Y, Hammond IG, McCartney AJ (2004) Total Laparoscopic hysterectomy for endometrial cancer: patterns of recurrence and survival. Gynecol Oncol 92:789-793

13. Obermeier A, Manolitsas TP, Leung Y, Hammond IG, McCartney AJ (2005) Total laparoscopic hysterectomy versus total abdominal hysterectomy for obese women with endometrial cancer. Int J Gynecol Cancer 15:319-324

14. Manolitsas TP, McCartney AJ (2002) Total laparoscopic hysterectomy in the management of endometrial carcinoma. J Am Assoc Gynecol Laparosc 9:54-62

15. Fagotti A, Ferrandina G, Longo R, Mancuso S, Scambia G (2002) Minilaparotomy in early stage endometrial cancer: an alternative to standard and laparoscopic treatment. Gynecol Oncol 86:177-183 
16. Occelli B, Samuelian V, Narducci F, Leblanc E, Querleu D (2003) The choice of approach in the surgical management of endometrial carcinoma: a retrospective series of 158 cases. Bull Cancer 90:347-355

17. Papadia A, Remorgida V, Salom EM, Ragni N (2004) Laparoscopic pelvic and paraaortic lymphadenectomy in gynecologic oncology. J Am Assoc Gynecol Laparosc 11:297-306

18. Marchiole P, Dargent D (2004) Laparoscopic lymphadenectomy and sentinel node biopsy in uterine cancer. Obstet Gynaecol Clin N Am 31:505-521

19. Leblanc E, Castelain B, Lanvin D, Querleu D (2000) Treatment of pelvic lymph node involvement in early stage cervical cancer. Gynecol Obstet Fertil 28:526-536

20. Querleu D, Leblanc E, Castelain B (1991) Laparoscopic pelvic lymphadenectomy. Am J Obstet Gynecol 164:579-581

21. Nezhat C, Burell M, Nezhat F (1992) Laparoscopic radical hysterectomy with paraaortic and pelvic node dissection. Am J Obstet Gynecol 166:864-865

22. Magrina JF, Serrano L, Cornella JL (1995) Laparoscopic lymphadenectomy and radical or modified radicalvaginal hysterectomy for endometrial and cervical carcinoma: preliminary experience. J Gynecol Surg 11:147-151

23. Kuopalla T, Tomas E, Heinonen PK (2004) Clinical outcome and complications of laparoscopic surgery compared with traditional surgery in women endometrial cancer. Arch Gynecol Obstet 270:25-30

24. Litta P, Fracas M, Pozzan C, Merlin F, Saccardi C, Sacco G (2003) Laparoscopic management of early stage endometrial cancer. Eur J Gynaecol Oncol 24:41-44

25. Kadar N (1995) Laparoscopic pelvic lymphadenectomy in obese women with gynecologic malignancies. J Am Assoc Gynecol Laparosc 2:163-167

26. Eltabbakh GH, Shamonki MI, Moody JM, Garafano LL (2000) Hysterectomy for obese women with endometrial cancer: laparoscopy or laparotomy? Gynecol Oncol 78:329-335

27. Kadar N (1997) Preliminary prospective observation on the laparoscopic management of endometrial carcinoma using the two-stage approach to aortic lymphadenectomy. J Am Assoc Gynecol Laparosc 4:443-448

28. Holub Z, Jabor A, Bartos P, Eim J, Kliment L (2001) Laparoscopic pelvic lymphadenectomy in the surgical treatment of endometrial cancer: results a multicentric study. J Soc Laparosc Surg 6:125-131

29. Gemignani MI, Curtin JP, Zelmanovich J, Patel DA, Venkatraman E, Barakat RR (1999) Laparoscopic-assisted vaginal hysterectomy for endometrial cancer: clinical outcome and hospital charges. Gynecol Oncol 73:5-11

30. Benedetti-Panici P, Maneschi F, Cutillo G, D'Andrea, Manci A, Rabitti C et al (1998) Anatomical and pathological study of retroperitoneal nodes in endometrial cancer. Int $\mathrm{J}$ Gynecol Cancer 8:322-327

31. Holub Z, Jabor A, Kliment L (2002) Comparison of two procedures for sentinel lymph node detection in patients with endometrial cancer: a pilot study. Eur J Gynecol Oncol 23:53-57

32. Burke TW, Levenback C, Tornos C, Morris M, Wharton JT, Gershenson DM (1996) Intraabdominal lymphatic mapping to direct selective pelvic and paraaortic lymphadenectomy in women with high-risk endometrial cancer: results of a pilot study. Gynecol Oncol 62:169-173

33. Morton DL, Wen DR, Wong JH, Economou JS, Cagle LA, Storm FK et al (1992) Technical details of intraoperative lymphatic mapping for early stage melanoma. Arch Surg 127:392-399

34. Pelosi E, Arena V, Baudino B, Bello M, Giusti M, Garguilo T et al (2003) Pre-operative lymphatic mapping and intra-operative sentinel lymph node detection in early stage endometrial cancer. Nucl Med Commun 24:971-975

35. Barranger E, Cortey A, Grahek D, Callard P, Uzan S, Darai E (2004) Laparoscopic sentinel node procedure using a combination of Patent blue and radiocolloid in women with endometrial cancer. Ann Surg Oncol 11:344-349

36. Lelievre L, Cammatte S, Le Frera-Belda MA, Kerrou K, Foisart M, Taurelle R et al (2004) Sentinel lymph node biopsy in cervix and corpus uteri cancers. Int J Gynecol Cancer 14:271-278
37. Niikura $\mathrm{H}$, Okamura Ch, Utsunomiya H, Yoshinaga K, Akahira J, Ito K et al (2004) Sentinel lymph node detection in patients with endometrial cancer. Gynecol Oncol 92:669-674

38. Raspagliesi F, Ditto A, Kusamura S, Fontanelli R, Vecchione F, Maccauro $M$ et al (2004) Hysterosopic injection of tracers in sentinel node detection of endometrial cancer: a feasibility study. Am J Obstet Gynecol 191:435-439

39. Dargent D, Martin X, Mathevet P (2000) Laparoscopic assessment of sentinel lymph node in early stage cervical cancer. Gynecol Oncol 79:411-415

40. Holub Z, Jabor A, Lukac J, Kliment L (2004) Laparoscopic detection of sentinel lymph nodes using blue dye in women with cervical and endometrial cancer. Med Sci Monit 10:587-591

41. Holub Z, Jabor A, Bartos P, Hendl J, Urbanek S (2003) Laparoscopic surgery in women with endometrial cancer: the learning curve. Eur J Obstet Gynecol Reprod Biol 107:195-200

42. Holub Z, Jabor A, Bartos P, Eim J, Urbanek S, Pivovarnikova R (2002) Laparoscopic surgery for endometrial cancer: long- term results of a multicentric study. Eur J Gynaecol Oncol 23:305-310

43. Magrina JF, Mutone NF, Weaver AL, Magtibay PM, Fowler RS, Cornell JL (1999) Laparoscopic lymphadenectomy and vaginal or laparoscopic hysterectomy with bilateral salpingooophorectomy for endometrial cancer: morbidity and survival. Am J Obstet Gynecol 181:376-381

44. Lim BK, Lavie 0, Balger B et al (2000) The role of laparoscopic surgery in the management of endometrial cancer. Br J Obstet Gynaecol 107:24-27

45. Eltabakkh GH (2000) Effect of surgeon's experience on the surgical outcome of laparoscopic surgery for women with endometrial cancer. Gynecol Oncol 78:58-61

46. Langebrekke A, Istre O, Hallquist AC, Hartgill TW, Onsrud M (2002) Comparison of laparoscopy and laparotomy in patients with endometrial cancer. J Am Assoc Gynecol Laparosc 9:152-157

47. Liauw L, Chung YN, Tsol CW, Pang CP, Cheung KB (2003) Laparoscopy for the treatment of women with endometrial cancer. Hong Kong Med J 9:108-112

48. Zapico A, Fuentes P, Grassa A, Arnanz F, Otazua J, CortesPrieto J (2005) Laparoscopic assisted vaginal hysterectomy versus abdominal hysterectomy in stage I and II endometrial cancer. Operating data, follow up and survival. Gynecol Oncol 98:222-227

49. Tozzi R, Malur S, Koehler Ch, Schneider A (2005) Laparoscopy versus laparotomy in endometrial cancer: first analysis of survival of a randomized prospective study. J Minim Invasive Gynecol 12:130-136

50. Wang PH, Yen MS, Yuan CC, Chao KC, Ng HT, Lee WL et al (1997) Port-site metastasis after laparoscopic assisted vaginal hysterectomy for endometrial cancer: possible mechanisms and prevention. Gynecol Oncol 66:51-55

51. Kadar N (1997) Port site recurrences following laparoscopic operations for gynaecological malignancies. $\mathrm{Br} \mathrm{J}$ Obstet Gynecol 10:1308-1313

52. Muntz H, Goff B, Madsen B, Yon JL (1999) Port site recurrence after laparoscopic surgery for endometrial carcinoma. Obstet Gynecol 93:807-809

53. Wilkinson NW, Shapiro AJ, Harvey SB, Stack RS, Cornum RL (2001) Port-site recurrence reproduced in the VX-2 rabbit carcinoma model: an in vivo model comparing laparoscopic port sites and open incisions. J Soc Laparoendosc Surg 5:221-226

54. Watson DI, Ellis T, Leeder PC, Neuhaus SJ, Dodd T, Jamieson GG (2003) Excision of laparoscopic port sites increases the likelihood of wound metastases in an experimental model. Surg Endosc 17:83-85

55. Sanjuan A, Hernandez S, Pahisa J, Ayuso A, Torne A, Roman $M$ et al (2005) Port site metastasis after laparoscopic surgery for endometrial carcinoma: two case reports. Gynecol Oncol 96:539-542

56. Spirtos NM, Schlaerth JB, Bross GM, Spirtos TW (1996) Cost and quality-of-life analysis of surgery for early endometrial cancer: laparotomy vs laparoscopy. Am J Obstet Gynecol $174: 1795-1800$ 
57. Scribner DR, Walker JL, Gary AJ, McMeekin SD, Gold MA, Mannel RS (2001) Surgical management o early-stage endometrial cancer in the elderly: is laparoscopy feasible? Gynecol Oncol 83:563-568
58. Holub Z, Voracek J, Shomani A (1998) A comparison of laparoscopic surgery with open procedure in endometrial cancer. Eur J Gynaec Oncol 19:294-297 